\title{
Comparative Evaluation of the Amount of Apical Extrusion of Bacteria from the Root Canal System Using Different Instrumentation Techniques: An In Vitro Study
}

\author{
Jambai S Sivakumar ${ }^{1}$, Ravi Vaiyapuri ${ }^{2}$, Brindha Loganathan ${ }^{3}$, Chittrarasu Mathimaraiselvan $^{4}$, Andamuthu Sivakumar $^{5}$,
} Anjaneya Shiva Prasad ${ }^{6}$

\begin{abstract}
Aim: To evaluate the amount of apical extrusion of bacteria from the root canal system following the use of different instrumentation techniques. Materials and methods: A total of 45 single-rooted mandibular premolar teeth were used. Access opening was done and root canals were then contaminated with a suspension of Enterococcus faecalis and then dried. The contaminated roots were divided into three experimental groups of 15 teeth each. Gl: Hand instrumentation. The root canals were instrumented using the K-file in the step-back technique. GIl: The root canals were instrumented using the Protaper Gold File system. GIII: The root canals were instrumented using the Mtwo File system. Bacteria extruded from the apical foramen during the instrumentation were collected in the vials. The resultant microbiological samples were removed from the vials and then incubated in culture media for 24 hours. The number of colony-forming units (CFU) was determined for each sample. The data obtained were analyzed using the Kruskal-Wallis one-way analysis of variance and Mann-Whitney U-tests, with $\alpha=0.05$ as the level for statistical significance.

Results: There was a significant difference between the rotary instrumentation technique and the hand instrumentation technique $(p<0.05)$. The hand instrumentation technique was associated with the greatest apical extrusion of bacteria.

Conclusion: All instrumentation techniques extruded intracanal bacteria apically. No significant difference was found in the number of CFU among the rotary instrumentation groups; the hand instrumentation technique extruded significantly more bacteria.

Keywords: Apical extrusion, Mtwo, ProTaper Gold, Rotary instrumentation techniques.

Journal of Operative Dentistry and Endodontics (2019): 10.5005/jp-journals-10047-0083
\end{abstract}

\section{INTRODUCTION}

The main objective of the root canal treatment is to clean the root canal system. During the canal preparation, necrotic tissue, pulp tissue remnants, dentin debris, microorganisms, and intracanal irrigants may be extruded from the root canal through the apical foramen. This is important because the bacteria extruded from the root canal into the periapex may be related to post-instrumentation complications. ${ }^{1}$

The shaping and cleaning of the root canal may involve the use of either hand files or engine operating systems, which may result in the transportation of the microorganisms through the apical foramen. This microbial extrusion is the most common cause of post-instrumentation flare-ups and also results in delayed healing. ${ }^{1}$

The inter-appointment flare-up is the common complication characterized by the development of pain, swelling, or both, which usually starts within a few hours or days after the root canal procedure. ${ }^{2}$ Flare-ups have been reported to have varying frequencies, ranging from 1.4 to $16 \% .^{3}$

The inter-appointment flare-ups may be due to mechanical, chemical, and microbial injury to the pulp or periradicular tissues. ${ }^{4}$ Mechanical and chemical injuries are commonly associated with iatrogenic factors. Overinstrumentation and overextended filling materials are often related to mechanical irritation that causes periradicular inflammation. Irrigants, intracanal medicaments, and overextended filling materials beyond apical foramen are mostly related to the chemical injury. ${ }^{5}$

\begin{abstract}
${ }^{1-6}$ Department of Conservative Dentistry and Endodontics, Vivekanandha Dental College for Women, Tiruchengode, Tamil Nadu, India

Corresponding Author: Brindha Loganathan, Department of Conservative Dentistry and Endodontics, Vivekanandha Dental College for Women, Tiruchengode, Tamil Nadu, India, Phone: +91 9488565206, e-mail: brindhaloganathan@yahoo.com

How to cite this article: Sivakumar JS, Vaiyapuri R, Loganathan B, et al. Comparative Evaluation of the Amount of Apical Extrusion of Bacteria from the Root Canal System Using Different Instrumentation Techniques: An In Vitro Study. J Oper Dent Endod 2019;4(2):88-91.

Source of support: Nil

Conflict of interest: None
\end{abstract}

However, the leakage of microorganisms and their by-products from the root canal system into the periradicular tissues results in microbial injury, which is the most frequent cause of interappointment flare-ups. ${ }^{6}$ The objective of this study was to compare the apical extrusion of bacteria from the root canal using different instrumentation techniques.

\section{Materials and Methods}

Forty-five human mandibular premolar teeth extracted for therapeutic reasons were collected. Periapical radiographs were taken to exclude teeth with calcification, internal resorption, or 


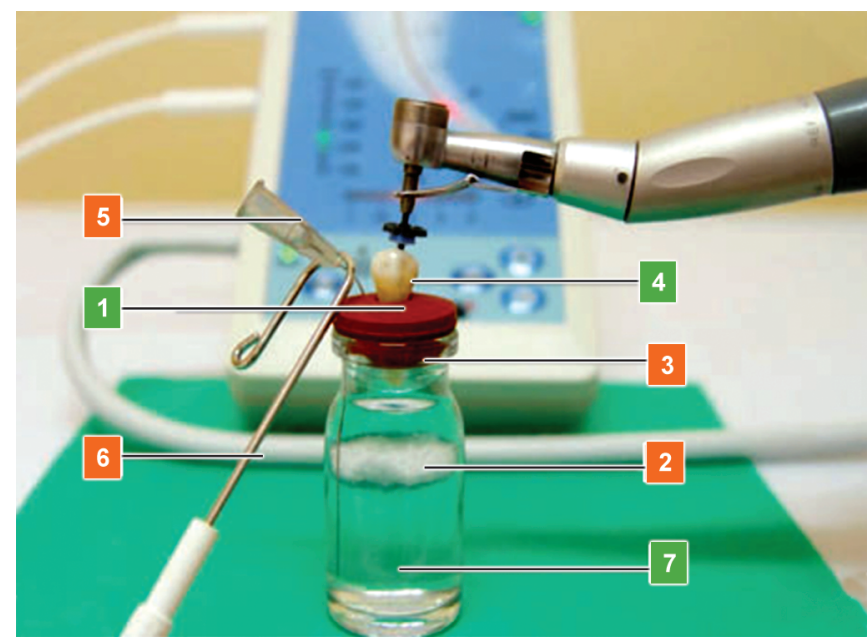

Fig. 1: Construction of test apparatus

any additional root canal. The methodology planned was through the following steps:

- Construction of the test apparatus

- Root canal contamination with E. faecalis

- Root canal preparation

- Bacterial count evaluation

\section{Construction of the "Test" Apparatus}

The test apparatus was constructed using a glass vial and a rubber stopper similar to the previously described method (Fig. 1). A heated instrument was used to create a hole through the center of the rubber stopper through which the tooth was inserted under pressure. After insertion, the cyanoacrylate cement was used to seal the gap between the tooth and the rubber stop at the cementoenamel junction.

To prevent the bacterial microleakage through the accessory and lateral canals, nail varnish was applied in two coats to the external surface of the roots. After the samples were coated, the rubber stops holding the tooth were fitted into the opening of the glass vial and the root was suspended within the vial. Thus, the vial act as a container for the extruding material through the apical foramen. The 27-gauge needle was used as a vent alongside the rubber stopper that serves two purposes. One, to equalize the air pressure inside and outside the vial and the other is to act as an electrode for an electronic apex locator for working length determination. The test apparatus along with the tooth samples were sterilized in ethylene oxide gas for a 12-hour cycle using anprolene and $74^{\circ} \mathrm{C}$ gas sterilizer before the commencement of the procedure. ${ }^{7}$

\section{Root Canal Contamination with E. faecalis}

The $E$. faecalis suspension was prepared by adding $1 \mathrm{~mL}$ of a pure culture of $E$. faecalis to the brain-heart infusion broth. Access opening was carried out in all the tooth samples. After the access preparation, the size of the apical foramen was standardized using a sterile 15 size K-file by breaching the apical foramen, thereby creating a hole in the nail varnish coat. The root canals were contaminated with a pure culture of E. faecalis strain (ATCC 29212) after the access opening (Fig. 2).

Contamination of the samples was carried out by filling the root canal with $E$. faecalis suspension using sterile micropipettes.

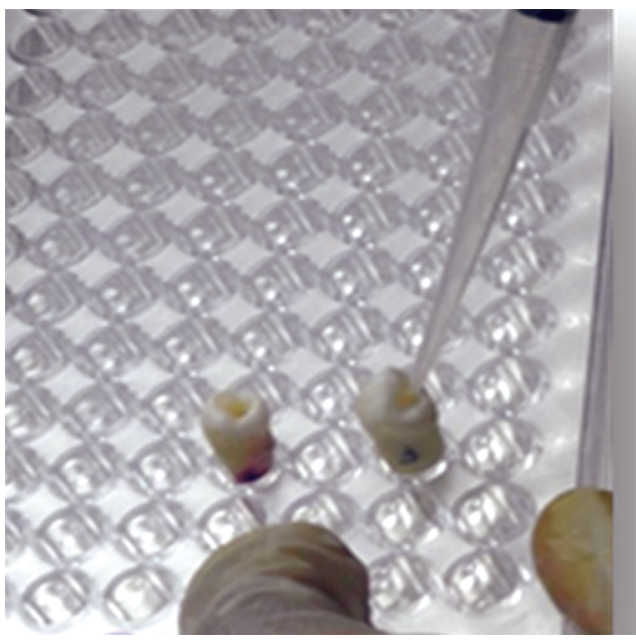

Fig. 2: Root canal contamination with $E$. faecalis

The 10 size K-file was used to carry the bacteria down the length of the root canals. After contamination, the root canals were incubated at $37^{\circ} \mathrm{C}$ for 24 hours. $^{7}$

\section{Root Canal Preparation}

After incubation, the contaminated samples were randomly divided into three groups and the procedure was carried out under a class I laminar airflow cabinet to prevent airborne bacterial contamination (Fig. 3).

- Group I: K-files using the step-back technique

- Group II: ProTaper Gold using the crown-down technique

- Group III: Mtwo using the crown-down technique

Working length was determined for all the teeth using the Propex Pixi apex locator with the $86.6 \%$ accuracy. The distilled water was used as an intermittent irrigant after each instrumentation, and is delivered using a 27-gauge disposable side-vented needle (maxi-I-probe), which was passively placed in the canal up to $3 \mathrm{~mm}$ short of the apical foramen without binding to the root canal walls.

\section{Bacterial Count Evaluation}

After completion of root canal preparation, $0.01 \mathrm{~mL}$ suspension was taken from the vial for bacterial culture; the suspension was plated on the brain-heart infusion agar at $37^{\circ} \mathrm{C}$ for 24 hours for incubation (Fig. 4). The classical method for evaluating bacterial count was used; the colonies of bacteria were interpreted as the number of colony-forming units (CFU) ${ }^{8}$ (Fig. 5).

\section{Statistical Analysis}

The collected data were statistically analyzed using the KruskalWallis one-way analysis of variance and Mann-Whitney $U$-tests and the statistical significance level was set at $p<0.05$.

\section{Results}

The mean number of apically extruded bacteria for all the groups is listed in Table 1. The value of the Kruskal-Wallis $H$ test is 16.2 , and the $p$ value is 0.0003 . Therefore, the result is significant at $p<0.05$. The results when compared group I and group II, group I showed a greater number of bacterial colonies compared to group II. Between group I and group III, the results showed group I with a greater number of bacterial colonies. Between group II and group III, group III showed a greater number of bacterial colonies. 


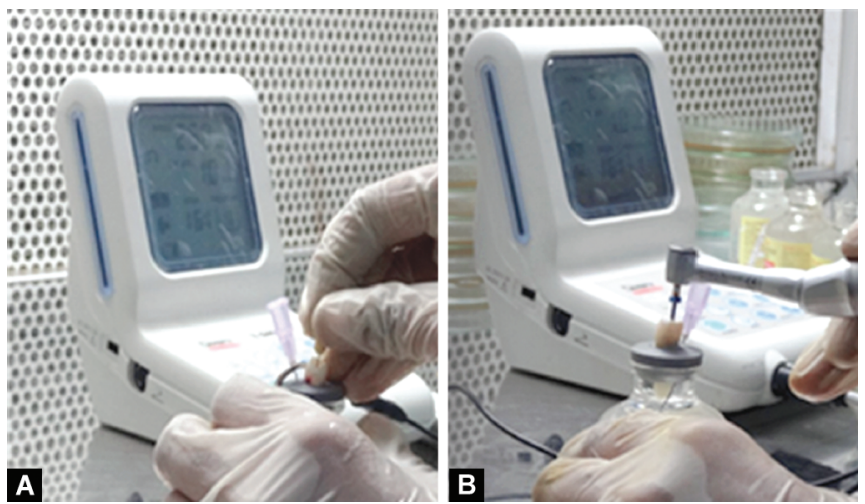

Figs $3 \mathrm{~A}$ and $\mathrm{B}$ : Root canal preparation under class I laminar airflow cabinet

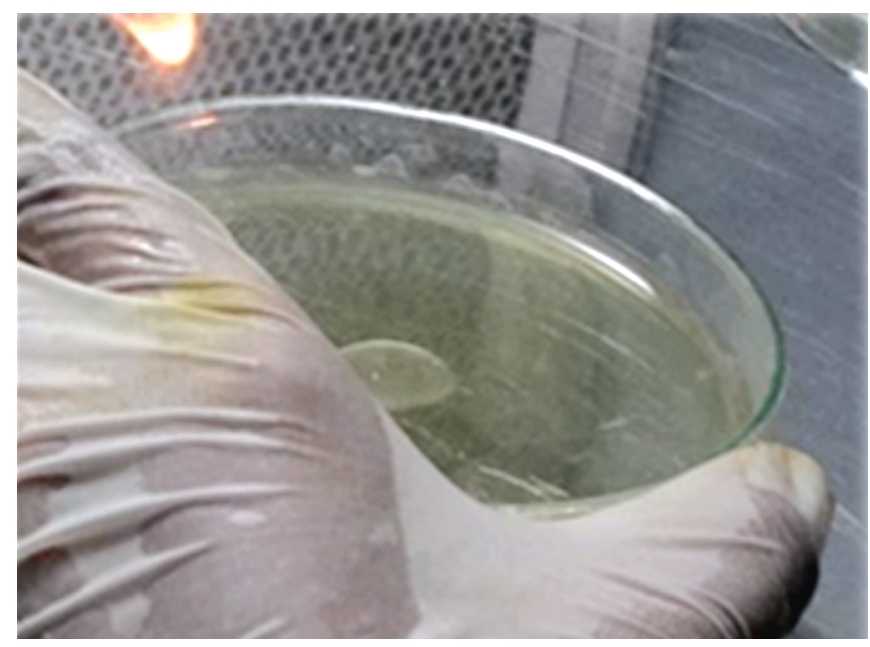

Fig. 4: $0.01 \mathrm{~mL}$ suspension was plated on the brain-heart infusion agar

There was a significant difference between the rotary instrumentation technique and the hand instrumentation technique $(p<0.05)$. But there was no significant difference between ProTaper and Mtwo rotary file systems. The results were graphically represented to show the mean differences between the three experimental groups (Fig. 6).

\section{Discussion}

In the literature, it is supported that infected as well as noninfected intracanal materials when forced apically during root canal preparation can trigger an inflammatory reaction. ${ }^{7}$ This inflammatory reaction also results in a flare-up and delayed healing depending upon the host responses. Because of these reasons, the extrusion of debris containing the bacteria is of primary concern. All the teeth selected in this study were mandibular premolar with a single straight canal, to decrease the variability among the samples.

The testing bacteria used in this study was $E$. faecalis because it is easy to grow, does not require special nutrients, and is an aerobic bacterium of significant clinical importance. E. faecalis has been reported to survive alone unlike other bacteria associated with root canal infections that may require symbiotic support from other bacteria for their growth. 9,10

In this study, working length was determined using the Propex Pixi apex locator. The working length for all the root canals was calculated and kept $0.5 \mathrm{~mm}$ short of the apical foramen. The selected master apical file for the manual instrumentation group is size $25 \mathrm{~K}$-file and for the rotary instrumentation groups was
$25 / 0.06$. In previous studies, it was reported that even sterile dentine debris that is pushed into the periapical area resulted in persistent inflammation. ${ }^{11}$ When performing a root canal treatment in the contaminated canals, the same situation may exist in a patient with a chronic pulpitis or pulp necrosis, especially in teeth with preexisting apical periodontitis. ${ }^{12}$

Seltzer and Naidorf reported that irritants in the form of chemically altered pulp tissue proteins into the granulomatous lesion have an adverse reaction that may follow. ${ }^{1}$ The presence of immunoglobulins in the periapical areas showed a relation to some of the antigens present in the canals. ${ }^{13}$ This clearly says that, if the canal contains the antigens and a granuloma has the antibodies, when intracanal contents are pushed from the canal to the periapical region, it will result in an antigen-antibody reaction. This immune reaction will cause damage to the cell membrane resulting in the release of prostaglandins, bone resorption, increased activity of the kinin system, and finally resulting in pain. ${ }^{14}$ It was also reported that some bacterial species that are resistant to the host defense have the potential to undergo inflammatory response and delayed healing. ${ }^{15}$ Therefore, it is important to possibly avoid or limit the bacterial debris extrusion of intracanal contents into the periradicular tissues.

The extrusion was observed with all the instrumentation techniques with the significant difference between the hand instrumentation and rotary instrumentation techniques. However, there was no significant difference between the two rotary instrumentation groups. The results are similar to the previous study reporting less bacterial extrusion in engine-driven nickel-titanium than the manual technique. ${ }^{16}$ This difference was possibly due to the cleaning and shaping instrument techniques and the file design. The crown-down technique used during the rotary instrumentation forces the debris out from the root canal coronally along the flutes of the file. The K-files when used in filing motion, the chances of the debris to be pushed apically were relatively greater.

The ProTaper Gold rotary file has a convex triangular crosssection and progressive taper, which allows the debris to move out coronally when the file is advanced toward the apex. The cross-section of the Mtwo rotary file is S-shaped, and the large and deep flutes allow for continuous upward transportation of dentinal debris. Therefore, between the ProTaper Gold and Mtwo rotary instrumentation techniques, there was no significant difference in the bacterial extrusion beyond the apical foramen.

\section{Conclusion}

Within the limitations of the study, all three groups were found to exhibit bacterial extrusion. But the hand instrumentation technique 

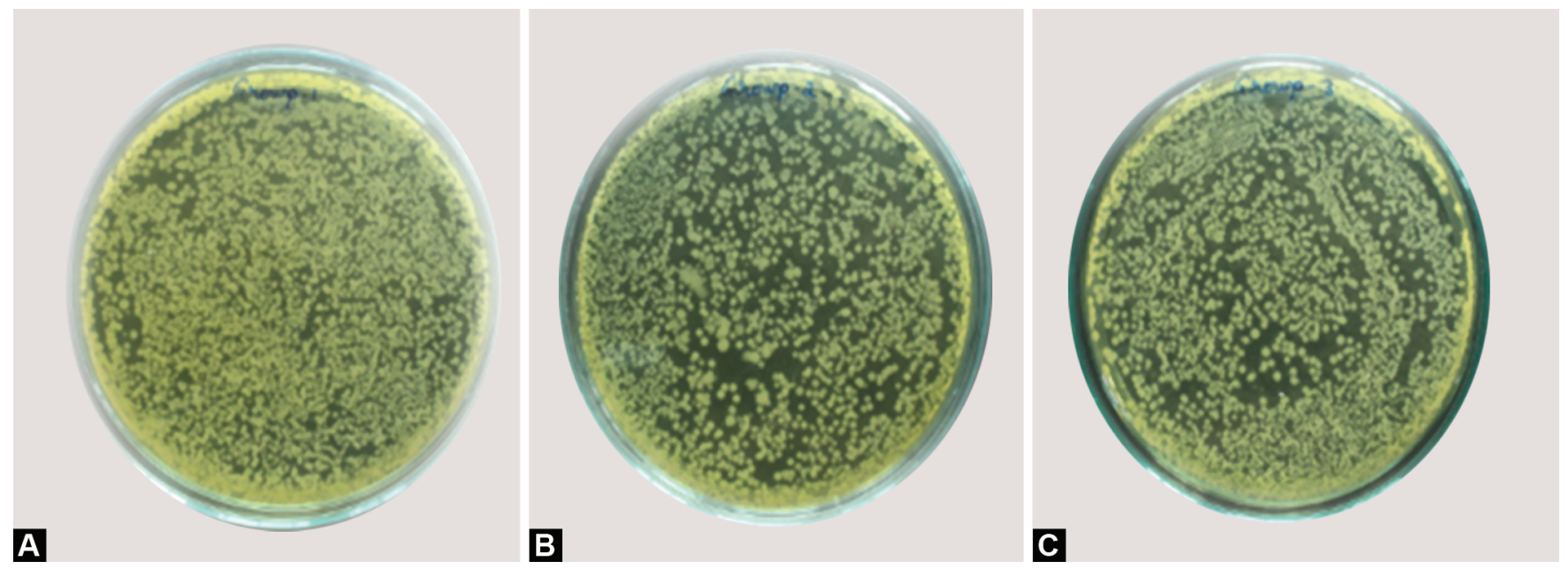

Figs 5A and C: Evaluation of bacterial count. (A) Group I (K-files); (B) Group II (ProTaper Gold); (C) Group III (Mtwo)

Table 1: Mean value of apically extruded bacteria

\begin{tabular}{llll}
\hline Groups & $\begin{array}{l}\text { Number of } \\
\text { samples }\end{array}$ & $\begin{array}{l}\text { CFU count } \\
\text { (mean value) }\end{array}$ & Mean \pm SD \\
\hline Group I & $n=15$ & 8.59 & $8.59 \pm 0.68$ \\
Group II & $n=15$ & 6.80 & $6.80 \pm 1.55$ \\
Group III & $n=15$ & 7.13 & $7.13 \pm 1.26$ \\
\hline
\end{tabular}

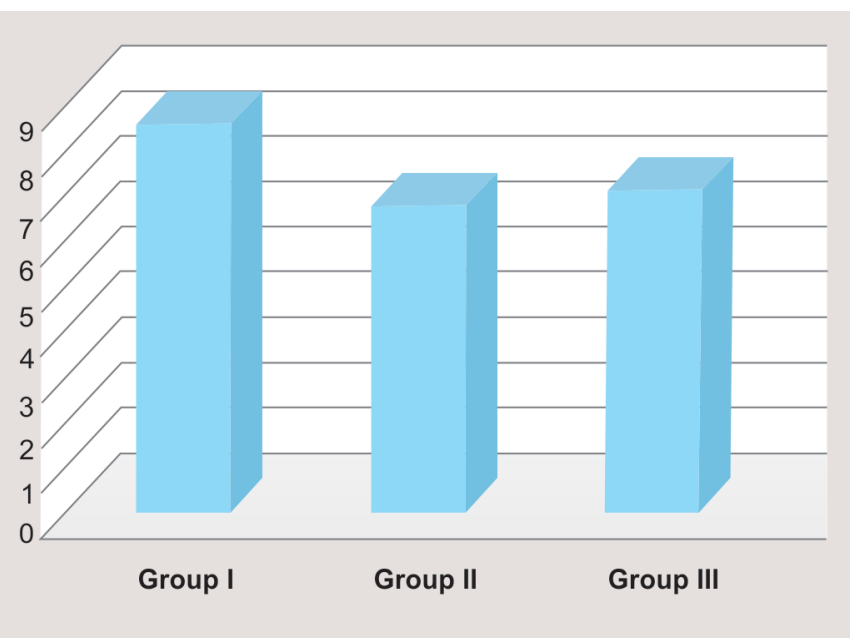

Fig. 6: Graphical representation of mean differences among the three experimental groups

showed significantly more amount of bacterial extrusion when compared to the rotary instrumentation technique.

\section{References}

1. Seltzer S, Naidorf IJ. Flare-ups in endodontics: etiological factors. J Endodont 1985;11(11):472-478. DOI: 10.1016/S0099-2399(85)80220-X.

2. Siqueira JF. Microbial cause of endodontic flare-ups. Int Endod J 2003;36(7):453-463. DOI: 10.1046/j.1365-2591.2003.00671.x.

3. Morse DR. Asymptomatic teeth with associated pulp and associated periapical radiolucencies: relation of endodontic flareups to endodontic instrumentation, antibiotic usage and stress in three separate practices at three different time periods. 1-5. Int J Psychosomat 1986;33(1):335-387.
4. Torabinejad M, Kettering JD, McGraw JC, et al. Factors associated with endodontic interappointment emergencies of teeth with necrotic pulps. J Endod 1988;14(5):261-266. DOI: 10.1016/S00992399(88)80181-X.

5. Kuştarci A, Akpinar KE, Sümer Z, et al. Apical extrusion of intracanal bacteria following use of various instrumentation techniques. Int Endodon J 2008;41(12):1066-1071. DOI: 10.1111/j.13652591.2008.01470.x.

6. Bartles HA, Noidarf IJ. A study of some associated factors associated with endodontic flare-ups. Oral Surg, Oral Med, Oral Pathol 1968;25(2):255-261. DOI: 10.1016/0030-4220(68)90287-9.

7. Er K, Sümer Z, Akpinar KE. Apical extrusion of intracanal bacteria following use of two engine-driven instrumentation techniques. Int Endod J 2005;38(12):871-876. DOI: 10.1111/j.1365-2591.2005. 01029.x.

8. Collins $\mathrm{CH}$. Microbiological Methods. 7th ed., Oxford, London: Butterworth Heinemann; 1995. pp. 149-162.

9. Dahlen G, Haapasalo M. Microbiology of apical periodontitis. In: Orstavik D, Pitt Ford TR. Essential Endodontology: Prevention and Treatment of Apical Periodontitis. 1st ed., Oxford, UK: Blackwell Sciences Ltd; 1998. pp. 106-125.

10. Portenier I, Waltimo TMT, Haapasalo M. Enterococcus faecalis - the root canal survivor and 'star' in post-treatment disease. Endodon Top 2003;6(1):135-159. DOI: 10.1111/j.1601-1546.2003.00040.x.

11. Seltzer S, Soltanoff W, Sinai I, et al. Biologic aspects of endodontics, 3. Periapical tissue reactions to root canal instrumentation. Oral Surg, Oral Med Oral Pathol 1968;26(4):534-546. DOI: 10.1016/00304220(68)90334-4.

12. Torneck CD, Smith JS, Grindall P. Biologic effect of endodontic procedures on developing incisor teeth. 3 . Effect of debridement and disinfection procedures in the treatment of experimentally induced pulp and periapical disease. Oral Surg, Oral Med, Oral Pathol 1973;;35(4):532-540. DOI: 10.1016/0030-4220(73)90011-x.

13. Naidorf IJ. Endodontic flare-ups: bacteriological and immunological mechanisms. J Endodont 1985;11(11):462-464. DOI: 10.1016/S00992399(85)80218-1.

14. Ruiz-Hubard EE, Gutmann JL, Wagner MJ. A quantitative assessment of canal debris forced periapically during root canal instrumentation using two different techniques. J Endodont 1987;13(12):554-558. DOI: 10.1016/S0099-2399(87)80004-3.

15. Kayaoglu G, Ørstavik D. Virulence factors of enterococcus faecalis: relationship to endodontic disease. Crit Rev Oral Biol Med 2004;15(5):308-320. DOI: 10.1177/154411130401500506.

16. Harish Kumar Shetty SK, Ravi Varma K, Prathap MS. Apical extrusion of bacteria from the root canal system following instrumentation-an ex vivo evaluation. Endodontol 2017. 46-54. 